\title{
Los decretos de la Real Hacienda de 1749 , los poderes locales y la representación del reino
}

\author{
Javier M. ${ }^{\text {a }}$ Donézar Diez de Ulzurrun *
}

\begin{abstract}
RESUMEN
Los Decretos de octubre de 1749

del marqués de la Ensenada

intentaron ordenar la fiscalidad de Castilla. En ellos se disponia, por un

lado, la sustitución de la variedad existente de impuestos por una Única

Contribución $y$, por otro,

su recaudación directa por parte de Hacienda hasta entonces gestionada por los Concejos.
\end{abstract}

Esta segunda medida iba a repercutir directamente sobre el poder y el control vecinal que desde hacia siglos venian ejerciendo las élites locales. A falta de convocatorias a Cortes, la general protesta de aquéllas se encauzó a través de la llamada Diputación del Reino, la cual redactó un escrito que presentó al rey Fernando VI y que resulta clave para entender por qué no llegó a aplicarse la Única.

\section{ABSTRACT}

The Marquis of Ensenada Bill, of october 1749, was meant to reform current taxes en Castille. With the new Law, te previous sigle taxation was replaced; and, on the other and, taxes collected - to then-by the Town Council were now direct responsability of the Ministry of Finance.

These changes were going to have repercussions on the neighbourhood's power and control, which had been lead by local community's elite for centuries. Non existing any more calls for Constituent Asembly, their members general protest was sent to the Country Authorities ('Diputación del Reino'). This official body wrote a document to the King Fernando VI, in fact the season why the single Act was never applied.

* Universidad Autónoma de Madrid. 
D. Zenón Somodevilla y Bengoechea, marqués de la Ensenada, como Ministro o Secretario de Hacienda y Guerra, de Marina e Indias del rey Fernando VI, publicó el 10 de octubre de 1749 unos Decretos que pretendian ordenar la fiscalidad de las 22 provincias de Castilla.

Se disponía en ellos, por una parte, la sustitución de los variados conceptos impositivos existentes (Rentas Provinciales) por una Única Contribución, la cual iba a suponer la elaboración de una magna encuesta previa (un Catastro); y, por otra, que en adelante Hacienda se iba a encargar de recaudar directamente los impuestos, hasta entonces administrados en régimen de arrendamiento.

Para el logro de tales objetivos se creaba la figura del Intendente-Corregidor provincial. Éste resultaba ser la prolongación de la Hacienda central al cual se le proporcionaba no sólo el poder de su representación -recaudación de los impuestos y puesta en marcha de la Única- sino el de Justicia y Policía con capacidad de solventar los recursos y castigar las más que esperadas reticencias de los contribuyentes:

"para advertir y excitar su obligación a las Justicias, y si no bastare, dar cuenta con justificación a las Chancillerias, Audiencias u otros Tribunales superiores a quienes corresponda según la calidad del negocio, para su debido castigo".

Contaría aquél con unos Subdelegados que, en una inmediata escala inferior, debian realizar los mismos cometidos; en las Respuestas Particulares del Catastro aparecen definidos como "Justicia mayor e Intendente general de todas las rentas reales y servicios de millones y tesoreria en la villa principal y su partido". Por ello, y desde el primer momento, estos nuevos personajes serían considerados por los Concejos como unos "ojos y oidos del Rey" arribados para dar cuenta y acabar con el defectuoso "orden" social impuesto a lo largo del tiempo por los poderes locales.

Por otra parte, y de un modo general, poner orden en los impuestos suponía remediar dos realidades; una, social: se intentaba redistribuir las cargas fiscales

"de forma que ninguno contribuya más de lo que le permitieren sus fuerzas, y que se haga a proporción de ellas, sin la exceptuación de que han gozado muchos contra lo que pide la justicia y la igualdad en el repartimiento y contribución" ";

Fernando Vl en la Ordenanza de Intendentes de 1749, cap. 62 . Recogido en la Novísima Recopilación, libro VI, tit. XXII, ley XVI.

Nota del autor. Las palabras o frases en cursiva que aparecen a lo largo de este artículo son subrayados mios. 
y otra, meramente económica, aumentar el monto total de los ingresos de Hacienda con respecto a lo que ésta habitualmente venía percibiendo. Por lo demás, con la Única y su procedimiento recaudatorio - cuya propaganda lo presentaba como "sencillo y nada complicado" - lo que se intentaba era alcanzar a percibir realmente una cantidad "equivalente" a la suma de las Rentas Provinciales y los tributos eclesiásticos.

Para quienes se consideraban tradicionalmente exentos de pagar impuestos de forma rutinaria resultaba verdaderamente revolucionario el aviso de que se iba a actuar "sin la exceptuación de que han gozado muchos...". De modo más preciso, esta actuación se iba a concretar en la puesta por escrito de la relación de las haciendas y haberes de todos los súbditos; esto era, también de los componentes de las oligarquías.

Algunos historiadores han mantenido que, en particular, el registro catastral de todos los bienes fue el asalto en toda regla a las economías privilegiadas y asi sigue siendo aceptado por la historiografía actual sobre el asunto. Sin embargo, puede afirmarse que fue mucho más, ya que dicho asalto económico encerraba claras connotaciones políticas; las tres medidas tomadas - cobro directo de los impuestos por Hacienda, la Única y su Catastro, y la figura del Intendente- se complementaban entre si para obtener el mismo fin, un intento de golpe de la nueva Monarquía absoluta propiciado por su ministro Ensenada contra los poderes locales y su institución-baluarte, las Cortes.

Éstas, para la comprensión de lo que aquí se aborda, deben ser entendidas tal y como, en realidad, eran; unas asambleas, según describe Juan Manuel Carretero, compuestas no por tres brazos diferenciados 0 tres realidades sociales distintas - nobleza, clero y "estado llano" - sino por una "clase social" formada por nobles, obispos, altos cargos de la administración y «burgueses», sin privilegio jurídico, representantes de las ciudades que coincidian, 'grosso modo' en intereses políticos, sociales y económicos, aunque esto no condujera en cada momento a una identidad absoluta de posiciones y comportamientos políticos ${ }^{2}$.

Y esto había sido así desde el principio de la Edad Moderna (a partir de las Cortes de Toledo de 1538 Carlos I decidió no convocar en adelante a los grandes señores y caballeros por la oposición que había encontrado en éstos a la implantación del impuesto de la sisa). Además, a partir de la segunda mitad del sigio xvi el interés de la nobleza por participar en el gobierno de las ciuda-

\footnotetext{
Carretero, Juan Manuel, Cortes, Monarquía, ciudades. Las Cortes de Castilla a comienzos de la época moderna (1476-1515). Madrid, 1988, págs. 419-421.
} 
des se hizo evidente; nobles e hidalgos fueron ocupando progresivamente los cargos concejiles de las ciudades y villas de realengo a través de dos vías: una la institucional, que había dividido a los regidores de los Ayuntamientos por mitad, y otra la compra de oficios, enajenados en masa por los Austrias. La primera databa de 1566 cuando Felipe II dispuso que los regidores

" del estado de los cabalieros hayan de ser hijosdalgo de sangre, y que ellos ni sus pasados no hayan tenido oficio mecánico ni vil, y que los del estado de ciudadanos hayan de ser hijosdalgos o a lo menos cristianos viejos, lim. pios, sin raza de moro ni judío".

No cabe duda que las regidurías, con un salario municipal por otra parte muy bajo, proporcionaban parcelas de poder político y dinero a sus compradores y descendientes; la prueba es que sus titulares las incluian de forma inmediata en el conjunto de los bienes amayorazgados, y los mismos reyes se servían de aquéllas para premiar servicios relevantes.

Las fuentes documentales - los protocolos notariales o el mismo Catastro para la Única - proporcionan numerosos ejemplos de lo acabado de señalar; entre ellos, hay uno con particular relevancia. En 1752 era regidor de Toledo el conde de Altamira, como poseedor de la casa y mayorazgo de Sanlúcar. El título, junto al de procurador extraordinario en Cortes, había sido concedido por Felipe IV al Conde-Duque de Olivares para sí y sus sucesores en 1640. Tal título, de regidor perpetuo, era válido para todas las ciudades y villa de voto en Cortes "donde os halláredes viviendo de asiento o estando de paso". Y ello en atención a los medios propuestos por Olivares "para la pacificación de los movimientos que algunos particulares intentaron en el muy noble y muy leal Señorio de Vizcaya...", e, igualmente, "en las alteraciones que algunas ciudades y villas del reino de Portugal hicieron (en 1637)". El Teniente de la regiduria nombrado por el conde de Altamira era D. Alberto Cid Dávila, caballero de la Orden de Santiago ${ }^{3}$.

He calificado la publicación de los Decretos de Ensenada como un intento de golpe de la aún no asentada dinastia dirigido contra los poderes fácticos del Reino; el ataque, si bien se analiza, estuvo dirigido de modo preferente contra los poderes urbanos más que contra los territoriales estamentales. Se indica esto porque, por un lado, ya desde la Alta Edad Moderna las actas de las Cortes castellanas registran pocos problemas específicamente nobiliarios o eclesiásticos; ello se debe, indudablemente, a que

DOnEzAR, Javier M. ${ }^{2}$, Riqueza y propiedad en la Castilla del Antiguo Régimen. 2. ${ }^{a}$ ed. revisada. Madrid, 1997, págs. 58-59. 
la Monarquía, para mantener el "pacto" con la nobleza y el clero desviaba sistemáticamente cualquier ataque dirigido contra sus intereses económicos y, además, como observa Pérez Prendes, porque "el rey tiende a absorber, por una evolución, los poderes de la nobleza y el alto clero"; lo cual significa que el monarca asumía la defensa nobiliaria y eclesiástica frente a las ciudades al haber hecho suyos los resortes de poder antes en manos de la nobleza ${ }^{4}$. $Y$, por otro, porque el ámbito geográfico de poder político y económico de los procuradores de una ciudad con voto en Cortes, y consecuentemente de los regidores que los designaban, no se circunscribia a su recinto urbano sino a todo el territorio o provincia dependiente.

Cierto es que la llegada de los Borbones cambió el panorama de la relación Rey-Reino (Cortes). Para los reyes ilustrados, con un régimen de gobierno sustentado en órganos ejecutivos y consultivo-administrativos y habiendo solventado expeditivamente la cuestión doctrinal del siglo anterior de si la Monarquía tenía pleno derecho a fijar por sí misma los tributos para subvenir a las necesidades públicas, las Cortes, como institución representativa para la gobernación, se convirtieron en la práctica en una entelequia. Con la nueva estructura entraron en estado durmiente; desaparecieron de derecho, aunque no de hecho, al ser privadas de asistir a la monarquía en los "hechos grandes y arduos" por ser sustituidas en este cometido por el Consejo de Estado y, muy principalmente, de la facultad de otorgar servicios.

Observa Juan Manuel Carretero cuán significativo es el hecho de que la Novísima Recopilación no recogiera una ley que aparecía en las Ordenanzas (lib. II, tit. XI, ley VI) y en la Nueva Recopilación (lib. VI, tit. VII, ley I) y que decía textualmente:

"Los reyes nuestros progenitores establecieron por leyes y ordenanzas fechas en Cortes, que no se echasen ni repartiesen ningunos pechos, servicios, pedidos, ni monedas, ni otros tributos nuevos, especial ni generalmente en todos nuestros reinos, sin que primeramente sean llamados a Cortes los procuradores de todas las ciudades y villas de nuestros reinos, y sean otorgados por los dichos procuradores que a las Cortes vinieren" ${ }^{5}$.

En la práctica, en el organigrama del gobierno ilustrado sólo quedaba de las Cortes una esquemática silueta: la que autodenominaron sus propios componentes "Diputación del Reino" o, de forma más grandilocuente, "Di-

\footnotetext{
4 Carretero, J.M., o.c., págs. 415-416 que cita a Pérez-Prendes, José Manuel, Cortes de Castilla. Barcelona, 1974, págs. 82-83.

5 CARRETERO, J.M., o.c., pág. 382 y nota de la misma página.
} 
putación de los Reinos de las Coronas de Castilla, León y Aragón". Para las ciudades, y a falta de convocatorias a Cortes, resultaba ser el único bastión institucional existente para hacer frente a las posibles veleidades del Rey y sus Ministros. De ahí que el título de Diputación respondiera más a un deseo de los poderes locales de no verse excluídos, como estaban, de las tomas de decisiones ministeriales que a otra cosa porque, por lo demás, el origen de aquélla había que encontrarlo en 1601 cuando se creó una Junta - Comisión de Millones de cuatro miembros upara despachar en nombre del Reino junto en Cortes" los asuntos de dicho servicio en el intervalo de tiempo existente hasta la siguiente convocatoria; más tarde, en 1713 se crearía una quinta plaza para los reinos de Aragón y Valencia. Siendo, por tanto, labor de sus cinco miembros representar a las ciudades en asuntos exclusivamente hacendísticos, y estando en minoría de votos desde Felipe $V$ dentro de la Sala de Millones y más tarde de la de Única Contribución, que un Decreto de Carlos III de 1770 hiciera referencia a los mismos Ilamándoles «Diputados del Reino» y otorgándoles rango de procuradores no pasaba de ser un reconocimiento oportunista en el momento tan delicado de poner en marcha desde arriba, una vez más, aquella Contribución ${ }^{6}$.

Que las Cortes no hubiesen sido convocadas por el Rey durante décadas para pactar concesiones de servicios de Millones y tratar sobre las Rentas provinciales, o que las cantidades anuales de unos y otras fueran consideradas como prorrogadas 'sine die' por Hacienda, con lo que significaba de pérdida de poder político para el Reino, fueron hechos que no levantaron demasiadas quejas entre los detentadores de los poderes municipales porque no alteraron sus particulares intereses. Hasta 1749 se opinaba que los Borbones estaban cambiando cosas pero que todo seguía igual; no había reuniones de Cortes pero los poderes fácticos que éstas representaban seguian incólumes. Sin embargo, la aparición de los Decretos en octubre de ese año provocaron un gran desasosiego porque revelaban que el siempre lejano gobierno central estaba dispuesto a quebrantarlos.

$Y$ todo porque aquéllos llegaban con la intención de poner punto final a una de las características esenciales de la fiscalidad del Antiguo Régimen, esto era, a la incapacidad de la administración central para gestionar directamente los recursos; la cual, por otra parte, se habia manifestado de modo especial cuando dichos recursos poseyeron una naturaleza directa $y$, en consecuencia y siempre en teoría, dependieron de la capacidad económica de cada uno de los vecinos.

$5 \quad$ Nov. Recop., libro III, tit. VIII, ley XV. 
Ante la ineptitud crónica de la administración central, la gestión final de los repartimientos del servicio se había erigido en una facultad más de los Concejos castellanos, esto es, de los grupos dirigentes o de los denominados "poderosos" por estar frecuentemente compuestos por los más ricos de las localidades. Esta forma de gestión, clave para proporcionar clientelas y dinero a los linajes detentadores de las regidurías, era la llamada a desaparecer al pretender Hacienda realizarla directamente esto era, por Intendentes y Subdelegados, siendo inevitable que con dicha desaparición cambiara de manos un control municipal que permanecia del mismo modo desde hacia más de dos siglos.

Para interpretar en su debida medida este cambio, y la oposición inmediata al mismo, es obligado explicar qué ventajas estaba proporcionando a los poderosos la gestión de las rentas. Resume con claridad J.M.Carretero que al quedar éstas bajo su responsabilidad sucedió lo que tenía que suceder: que aquéllos (que eran regidores y que, con un más que notable orden para el bien de todos ellos, se repartían las procuradurías de Cortes, o sea, que negociaban directamente con la monarquía los cupos para su distrito) fueron diseñando toda una serie de estrategias tendentes a anular el carácter directo de las contribuciones, por cuanto ellos teóricamente eran los que más tenian que pagar ${ }^{7}$.

La Hacienda real, desde el principio, había sido plenamente consciente de que las oligarquias locales no habian observado la naturaleza fiscal de los servicios y de que habían desarrollado todo un sistema de irregularidades para salvaguardar sus rentas en detrimento de los pecheros con menor capacidad económica, pero había preferido mirar para otro lado. A raiz de los informes de los pesquisidores mandados hacer por la Contaduría mayor en 1528-1530, en los que se evidenció que los repartimientos eran patrimonio de los regidores y de los pecheros más ricos para no sólo pagar apenas nada sino beneficiarse en detrimento siempre de los débiles, se volvieron a recordar antiguas normas que, evidentemente, no fueron cumplidas. Es más, el hecho de que la principal de ellas, que desde 1349 prohibia a las Justicias y Regidores arrendar las rentas reales y las de propios de los pueblos - «ni por sí ni por interpósitas personas"-, esté recogida en la Novísima Recopilación es la prueba más fehaciente de tal incumpliento ${ }^{8}$. Porque la monarquía no solamente careció de capacidad de gestión sino que antepuso

\footnotetext{
7 Ver el interesante artículo de J.M. CARRETERO, "Poder municipal, oligarquias y mecanismos de repartimiento y pago de los servicios de cortes en época de Carlos V", en ARANDA, Fco. José (Coord.), Poderes intermedios, poderes interpuestos, sociedad y oligarquias en la España Moderna. Cuenca, 1999, págs. 106-146.

8 Nov. Recop., libro VII, tit. IX, ley VII.
} 
las necesidades recaudatorias a cualquier disquisición sobre moral fiscal y estableció un pacto no escrito: recibiría con puntualidad las cantidades otorgadas por las Cortes y, a cambio, cedía a los poderosos la gestión de los servicios incluyendo hacer la vista gorda sobre los procedimientos.

Y este pacto permaneció a lo largo de la Edad Moderna desde los primeros servicios de Cortes de Carlos I a los de Millones o las Rentas Provinciales. En el primer servicio de Millones de 1590

"se previno que la cobranza y administración de ellos había de correr por los Procuradores del Reino (esto era, por los regidores de las ciudades). Y en el segundo de 1597 fue condición que la administración y distribución de ellos fuese privativa del Reino y las receptorias se diesen a las Ciudades para que nombraran personas que cobrasen y pagasen (...). En el tercer servicio del año de 1600 se capituló que su recaudación corriese a cargo del Reino" ${ }^{9}$.

El sistema, con sus abusos inherentes y que explica, por ejemplo, el interés de la nobleza por participar en él, pudo mantenerse porque dichas oligarquías hicieron partícipes de esas irregularidades a amplios sectores del mundo urbano mediante fórmulas no carentes de originalidad o mediante la interpretación parcial de antiguos usos heredados del mundo medieval: declarando hidalguías universales, eximiendo a núcleos urbanos por entero sirviéndose del concepto "de muros adentro", entablando pleitos interminables contra la Contaduría aduciendo antiguos privilegios de exención (mientras se sustanciaban se evitaba su pago), haciendo exentos de las cargas concejiles a familiares, amigos o clientes y, sobre todo, alterando la naturaleza fiscal del servicio convirtiendo en indirecta la que en origen había sido una prestación directa sobre los haberes de cada cual ${ }^{10}$.

Ha de decirse, pues, que si el control político-económico de las oligarquías tuvo como pilares principales la asignación caprichosa de la cantidad impositiva a los contribuyentes y la alteración de la forma de cobro de los mismos - esto era, mientras se mantenía su naturaleza de tributación directa eran cobrados como si fueran indirectos-, en justamente lo contrario se basó la reforma de Ensenada, a saber, en que todo el mundo participara en las cargas del Estado mediante una Única Contribución.

Uno de los métodos preferidos para la formación de clientelas fue la cuestión de las exenciones de cargas. Se ha escrito arriba que las angustias y estrecheces hacendisticas que padecieron los monarcas beneficia-

9 Nov. Recop., En Notas a lib. VI, tit. X, leyes III, IV y V sobre el Consejo de Hacienda, Contaduria mayor de Rentas y Sala de Millones.

10 Carretero, J.M., “Poder municipal...”, pág. 111 
ron a las oligarquías locales de modo que éstas pudieron obrar a su más completo antojo, por eso su primera decisión fue lograr la exención total o parcial para ellas mismas, sus familias..., y los amigos que eran incorporados a los clanes familiares. Menciona J. M. Carretero que uno de los ejemplos más conocido hacia 1530 había sido el de los Linajes de Segovia; en las Averiguaciones de esa provincia se escribía:

“... porque cada regidor o persona que tiene favor en el regimiento, hace meter a sus criados y allegados (...), y al presente están en los dichos Linajes 1.013 personas, con hijos y criados, casados y no casados, como parece por las fes de los escribanos de los dichos Linajes que están en el libro de la dicha averiguación junto a los padrones de la dicha ciudad de Segovia".

Y la razón última por la que no pagaban impuestos era porque detentaban oficios del Concejo; a falta de otro argumento juridico, diseñaron una norma: toda persona con oficio de gobierno estaba exenta por el mero hecho de ejercerlo. Y como la reiteración crea costumbre, se originó un resquicio legal con el que sustentar tales prácticas; dicho resquicio permitió que en la exención fueran también incluidos los arrendatarios de la tierra al defender que tal parcela estaba exenta porque exento era su propietario ".

En 1566, con motivo de haberse autodeclarado exentos los escribanos de Arévalo y de otros pueblos con sus hijos y descendientes, Felipe II tuvo que ordenar que

"de aquí adelante todos y cualesquier Escribanos del Número o del Concejo, asi de la dicha villa de Arévalo como de todas las otras ciudades, villas y lugares de estos Reinos y Señorios, por razón de los dichos no puedan gozar ni gocen de cualquier exención de pechos ellos ni sus hijos ni descendientes (...); y lo mismo mandamos que se cumpla y guarde en cuanto a los Regidores y Jurados y otros oficiales del Concejo de estos Reinos, los cuales por razón de sus oficios no se puedan excusar ni excusen de pechar...".

Tal Orden no debió ser demasiado atendida puesto que, como otras, fue recogida más tarde por la Novísima Recopilación ${ }^{12}$.

La razón de "trabajar para la Ciudad" fue excusa muy habitual para que determinados grupos de población fueran declarados exentos por los Concejos. En determinadas poblaciones llegaron a serlo los boticarios, los

Carretero, J.M., "Poder municipal...", pág. 113.

Nov. Recop., libro VI, tit. XVIII, ley XVIII. 
hospitaleros, los barberos o los pregoneros... Felipe $V$ en una Provisión de marzo de 1743 se refería a que había

"un abuso de exentos", de personas exentas de oficios y cargas concejiles, por lo que estas recaian "sobre los vecinos pobres y que menos pueden llevarlas (...), que no pudiendo los vecinos pobres sobrellevar solos tan pesadas cargas, se ven precisados a desamparar sus casas y lugares metiéndose a mendigos; de que se sigue sin duda, además de los perjuicios que ocasiona la gente ociosa, verse tantos pueblos arruinados y sin ente para el cultivo de los campos y otros ministerios precisos...".

Y se citaban como eximidos los ministros y hospederos de Cruzada, familiares del Santo Oficio, síndicos de religiones, recogedores y guardas de Rentas reales, estanqueros de naipes, tabaco, pólvora y otros géneros, salitreros, dueños de yeguas, comisarios de las Santas Hermandades...

En dicha Provisión se aludía al gran número existente de títulos de ministros (arrendadores) de Rentas - cuya tenencia convertía a sus propietarios en exentos- y al tráfico existente para obtenerlos; precisamente eran los regidores de las ciudades y villas los encargados de otorgarlos, los cuales solían hacerlo o por amistad (para asegurarse futuros favores) o a cambio de una oculta cantidad de dinero. Así, a

"la abusiva negociación que se hace por muchos vecinos acomodados para obtener semejantes títulos de arrendadores de rentas Reales, y otros que alegan tener facultad para concederlos, de la cual se valen para establecerlos sin necesidad aun en pueblos de corta población, de que se reconoce con evidencia no ser otro el fin de la solicitud de estos títulos que la utilidad de gozar exención en las referidas cargas..." ${ }^{13}$.

E incluso algunos Concejos para ganarse la adhesión inquebrantable de sus vecinos llegaron a proponer la "hidalguía universal» (fue el caso de las Cuatro Villas de la Mar) a fin de que todos quedaran exentos siguiendo el proceso inverso al de las llamadas Provincias Exentas; porque éstas, aprovechando los privilegios que otorgaban las instituciones castellanas a sus hidalgos y al no tener que pagar impuestos comunes a la monarquía por causa de sus fueros, habían concluido que todos sus vecinos eran "hidalgos" al modo de Castilla.

$Y$ puesto que los regidores eran los encargados de reunir los impuestos no sólo de su ciudad o villa sino de todo el distrito asignado a éstas, la compensación a tanta exención solía consistir en endosar el grueso de la carga fiscal a los lugares incluidos en aquél.

13 Nov. Recop., libro VI, tit. XVIII, ley XXI. 
Quizás lo que más influyó para que los vecinos aceptaran la permanencia de las élites en los oficios concejiles fue el cambio introducido por éstas en la naturaleza de los impuestos o en la forma de su cobro con respecto a la propuesta por las Contadurias generales de Rentas. Así, los Concejos aprovechando sus amplias facultades en el cobro de los servicios propusieron mecanismos de pago alternativos al de capitación y la excusa ofrecida a la monarquía fue la misma que permanecería hasta el siglo $x x$ : la ausencia de padrones fiables, sobre todo de las ciudades. La verdad es que esta justificación siempre fue suficiente para una monarquía que por estar perentoriamente necesitada de dinero no se entretuvo demasiado en indagar su procedencia.

Asi que, dejadas de lado las inevitables quejas de celosos funcionarios, dicha excusa sirvió también de estratagema para que las cantidades asignadas a las ciudades fueran más fruto de los tratos de los gobernantes de éstas con Hacienda que el resultado objetivo derivado de un conocimiento demográfico y económico. En este punto no está de más recalcar algo ya señalado para entender el golpe que pudo suponer la elaboración del Catastro de 1749: que los distintos procedimientos utilizados a lo largo del tiempo siempre tendieron a impedir que el impuesto fuera proporcional a los bienes de los individuos por lo cual aquéllos, también siempre, fueron bien acogidos por los vecinos o por lo menos mejor que los que tenían como base el encabezamiento.

Es evidente que tales métodos alternativos solamente se aplicaron en los núcleos con una población significativa quedando la capitación únicamente para los casos en que con aquéllos no se hubiese llegado a alcanzar la cantidad estipulada; mientras, en los núcleos pequeños toda fórmula distinta a la citada capitación era inviable. La poca extensión de los términos municipales impedía la existencia de arrendamientos de tierras de propios, o la poca población el mantenimiento de servicios (mesones, tabernas, molinos) que proporcionaran rentas concejiles; la misma estructura del consumo interno hacía imposible el establecimiento de sisas sobre productos básicos por cuanto el campesinado no iba a comprar (y pagar la correspondiente sisa) los bienes que él mismo producia.

Así pues, el establecimiento de sisas o el arrendamiento de los bienes inmuebles de propios fueron los recursos preferidos por los Ayuntamientos de entidad. Si bien se mira eran éstas unas opciones que convenian a todo el mundo: a Hacienda porque se le garantizaba una percepción segura de la cantidad establecida y sin dilación, a los regidores y justicias porque evitaban contribuir por sus bienes y mantenian su influencia social 
al no tener que exigir los impuestos casa por casa, y a los vecinos porque les parecía que o no pagaban o que pagaban menos.

Al principio, fueron ciudades aisladas las que procedieron de este modo pero luego estos métodos se generalizaron sobre todo cuando, a raiz de la revuelta de las Comunidades y su coronación como Emperador, Carlos I autorizó a que se recaudaran los servicios "por los medios que fuere y más presto se cobrase" ${ }^{14}$.

La sisa, en particular, gozó de especial predicamento como mecanismo recaudatorio e incluso fue presentada bajo la aureola de la «igualdad» porque teóricamente tenían que pagarla todas las clases sociales cuando se acercaran a comprar determinados productos; desde luego era un impuesto muy repartido porque en él participaban además de los vecinos de la ciudad los foranos que habían llegado a ella para comerciar. Los gobernantes enseguida vislumbraron en su cobro nuevas posibilidades, y entre otras no menores la de arrendarlas para evitar gastos al municipio, incluyendo la designación interesada de sus arrendadores, o la de generar "sobras" a base de exigir el ingreso en las arcas del Ayuntamiento de una cantidad mayor a la destinada para pagar a Hacienda; tales excedentes eran utilizados para pagar pleitos, salarios, ayudas de costa $u$ otros gastos a discreción de los regidores.

Lo de las «sobras» acabó originando más perjuicios que beneficios y fue fuente de frecuentes quejas porque encarecía los productos básicos, así que desde la monarquía se recomendó que los pagos se hicieran con las rentas de Propios. Al respecto, hay que añadir que la creación de excedentes sobre las cantidades fijadas de antemano, y la participación en ellos de los oficios concejiles, estuvo detrás del cobro de las variadas rentas en régimen de arrendamiento, que eran prácticamente todas.

El mismo encargo del cobro de las rentas Reales otorgaba a los regidores y justicias una participación en las mismas que hasta 1687 fue del cinco por ciento, año en que subió al seis por ciento. Carlos II lo dispuso mediante una resolución en premio a la labor «... así por la ocupación de la cobranza, como por el coste de la conducción que fuere necesaria para llevar el dinero a las cabezas del partido, donde se hubieren de hacer las pagas de las contribuciones y servicios". En la misma resolución se reconocia la existencia de toda una red clientelar alrededor de aquellos regidores y justicias para el cobro porque se les exigía que debian salir fiadores de las personas que nombraran para su realización práctica, así como de

14 Cafretero, J.M., "Poder municipal...", págs. 120 y ss. 
las que designaran "para la administración del Pósito, Propios de las villas y lugares, repartimiento de las bulas y su cobranza, repartimiento de puentes, y acopiamiento de la sal y otros cualesquiera pedidos"; también debían salir fiadores de los arrendadores de las alcabalas y cientos ${ }^{15}$.

Ante las múltiples quejas sobre la forma en que los regidores y justicias cobraban las rentas, en 1725 Felipe $V$ se vio obligado a dar una Instrucción sobre cómo debía procederse «sin vejaciones de los pueblos» ${ }^{16}$. Era el escrito un informe realizado por una Junta formada el año anterior en el que se ponían de relieve los abusos más frecuentes. Obviamente, las quejas de los vecinos habian girado alrededor de las cantidades recaudadas por el procedimiento del encabezamiento.

Porque era común en las ciudades y villas que sus Concejos encabezasen todos los años una cantidad arbitraria, aunque no fuera precisa para el pago de las rentas Reales, que ayudara a «redondear» el seis por ciento establecido de los regidores y justicias. Bastaba con afirmar -mostrando cifras ficticias en los libros de cuentas- que en ese año se había obtenido poco de los arbitrios por compras y ventas por lo que era preciso proceder a repartir la diferencia.

Y a este abuso colaboraba otro abuso; porque el mencionado reparto recaía en los vecinos más débiles librándose los oficios concejiles y sus clientelas, puesto que eran los encargados de hacer las listas de los contribuyentes para el mismo. Y lo mismo sucedía en los pueblos pequeños cuyas listas eran confeccionadas por individuos llegados de los lugares de cabecera. Se decía en la Instrucción:

"Si el todo de sus encabezamientos, con más el expresado seis por ciento, lo cargaren en las carnicerias, tiendas de abasto, mesones y otros puestos públicos, y por no alcanzar su producto fuese necesario repartimiento, to hagan sólo de la cantidad que faltare; y en éste (...) han de incluir a todos los vecinos y residentes con hacienda o tratos, Justicias, Regidores y Escribanos, sin reserva de alguno, ejecutándolos en proporción de las haciendas, ganados, frutos, ventas y consumos, tratos y comercios de cada uno; con declaración de que a los pobres de solemnidad y jornaleros no hacendados no han de poder repartir ni repartan cantidad alguna".

Pretendía Hacienda que le fuera entregada una copia del listado de los vecinos a fin de proceder con justicia; la intención era buena pero podía quedar sólo en eso si no existía en los Concejos una voluntad de entregar

Nov. Recop., libro VI, tit. XXII, ley XII.

Nov. Recop., libro VI, tit. XXII, ley XV. 
padrones fiables. Los regidores y demás oficios y amigos o podían "caerse" de los mismos, como solía suceder, o podían no proporcionar una valoración objetiva de su riqueza. O incluso podian optar por colocarse al final de las listas; y esto que, aparentemente, parece significar poco tenía su por qué, en especial en los casos en que habia la necesidad real, no fingida, de repartir la cantidad que faltaba para completar la total. Porque con listas completas de los vecinos y procediendo a recaudar siguiendo el orden establecido en las mismas era más que probable que no hiciera falta llegar a los últimos para obtener el monto pretendido. Pero instalarse al final en las listas también procuraba otras ventajas como la de cobrar a los primeros contribuyentes de las listas, quedarse con el dinero para sus usos particulares ocultando que había sido cobrado para o volvérselo a cobrar o solicitar al rey remisión de la deuda para todos los vecinos -ellos mismos incluidos - alegando no haber podido juntar la cantidad comprometida. Para solventar lo cual se señalaba:

"Habiendo enseñado la experiencia que en muchos pueblos los Alcaldes y Regidores cobran de los primeros contribuyentes (de la lista), que suelen no anotar en los libros cobradores y acaso cobrarlas duplicadamente por malicia u olvido, y debiendo ponerlas en arcas las convierten en sus usos, lo que pide debido remedio; y para que to haya en lo futuro, se ordena que cuando vayan a cobrar lleven el libro cobrador, en el que inmediatamente sienten la partida que cada vecino entregare; y no llevándolo, no puedan obligarlos a la paga de su repartimiento, y dando recibos a todos los vecinos que los pidieren...".

Como las solicitudes de remisión de deudas y su seguimiento solían acarrear muchos gastos a los pueblos, era costumbre hacer una derrama entre todos los vecinos, de cuyas listas los poderosos del Concejo o procuraban escapar o pagar menos incluyendo en éstas también a los más débiles. Tan era así que en la Instrucción se ordenaba, por un lado, "que no puedan incluir ni incluyan en ellos (en los pagos de los gastos) a los pobres ni a jornaleros que por no tener hacienda ni trato lo son, ni a otros vecinos que los que fueren deudores de las cantidades comprendidas en las tales remisiones"; $y$, por otro, si se diera el caso de que a los vecinos les fuera concedida la remisión pedida "no se entiendan comprendidas las partidas repartidas a los dichos Alcaldes, Regidores, Escribanos y demás ministros de Justicia, sus padres y hermanos".

La Instrucción de Felipe $V$ resultó poco útil para la eliminación de unas prácticas abusivas plenamente enraizadas en la vida cotidiana de las gentes porque no constituyó un ataque frontal a los poderes locales al permitir que éstos siguieran encargándose del cobro de las rentas. No obstante, sirvió de punto de partida para que los gobiernos ilustrados tomaran en serio la cuestión de tomar medidas auténticamente reformistas. 
Los Decretos de octubre de 1749 llegaron de forma sorpresiva, como no podía ser de otro modo, a fin de no prevenir a los que acaparaban los instrumentos para frenarlos; además, no cabe duda que a ello influyó lo que le había sucedido a Felipe IV cuando por pedir el parecer de las Cortes sobre su intento de implantar un sistema fiscal "universal» - precedente riguroso de la Única Contribución-, éste fue relegado respetuosamente al olvido.

Pero también resultó una sorpresa para las oligarquías el hecho de su inmediata aplicación; fueron nombrados los nuevos Intendentes provinciales y sus Subdelegados y casi al día siguiente empezaron a actuar con arreglo a los capítulos de su nueva Ordenanza. Una red de comisionados por éstos, y con salarios a cargo de Hacienda, comenzaron a un tiempo a expandirse por los pueblos de las 22 provincias de Castilla para elaborar un Catastro - o fijar por escrito las relaciones de bienes de todos los súbditos, esto era, también de los nobles y eclesiásticos - que fuera la referencia para imponer una Única Contribución, basada en la capitación proporcional a dichos bienes, que sustituyera a las Rentas Provinciales. Hasta que no finalizaran los trabajos del Catastro, por tanto, seguirían funcionando éstas.

Que por una vez las reformas iban en serio lo comprobaron los dirigentes de los Concejos cuando a partir del primero de enero de 1750 el cobro de las Rentas pasó a manos de los Intendentes y Subdelegados. Éstos debian nombrar como perceptores directos de las mismas en las ciudades y villas a los Corregidores, Regidores y Justicias que juzgaran "convenientes", con lo cual se rompía el bloque de poder de «Regidores y Justicias» al quedar éste a disposición de aquéllos. Ante la imposibilidad de cambiar de un golpe a los recaudadores, y puesto que permanecían las Rentas Provinciales, pareció prudente aprovechar temporalmente su experiencia si bien se les sometió a un control. En el capítulo 46 de la Ordenanza se decía:

"Con no menos atención deberán (los Intendentes) inquirir y averiguar secreta y reservadamente la forma y justificación con que las Justicias proceden en la exacción de los derechos Reales, arrendamiento y administración de los ramos y puestos públicos, y los repartimientos que hicieren a los vecinos para cubrir el importe o ajuste de los encabezamientos; si se arreglan a la referida Instrucción y Cédula de 13 de marzo de 1725; examinando los bienes raíces, rentas, tratos, negociaciones y granjerias de cada uno, para obrar en la repartición con la proporción y justicia correspondiente; si gravan o no a los pobres y jornaleros no hacendados; procurando, sin omitir fatiga alguna, en que por noble, poderoso, ni con otro pretexto alguno nadie se excuse de contribuir y concurrir al repartimiento con lo correspondiente a sus haberes".

Y en el cap. 49 se añadía que ya que los Alcaldes, Regidores y Justicias cobraban el seis por ciento por su labor de recaudación, serian 
responsables con sus bienes, y nadie más, de todas las demoras en el cobro y entrega de las cantidades recaudadas en los plazos previstos.

\section{LA REPRESENTACIÓN DE LA DIPUTACIÓN DEL REINO}

Era de esperar que la aplicación de medidas «revolucionarias» desde la monarquía enarbolando la bandera de la Justicia, que eliminaban inmunidades ancestrales en favor de la «igualdad» social o acababan con el poder real de los Concejos, provocara el inmediato rechazo de los poderosos, como así fue.

Mientras duró la elaboración del Catastro, la oposición estuvo organizada como clase y fue eficaz moviéndose en diferentes frentes: introdujo en todos los grupos sociales un generalizado "miedo" a que Hacienda se enterase de lo que tenía cada cual, corrió la especie de que con la Única se iba a pagar más de lo que se estaba pagando con las rentas Provinciales a pesar de que el gobierno defendiera que la cantidad final sería un "equivalente" - lo cual resultaba cierto para los que nunca habian pagado-, adhirió al clero regular en el movimiento porque tampoco nunca había contribuído, intrigó en la Corte para que cayera el promotor de las reformas Ensenada y, ya en el ámbito de lo cotidiano, se dedicó a poner continuas trabas a los funcionarios en orden a retrasar la finalización del Catastro puesto que ésta era requisito indispensable para la entrada de la Única. En definitiva, nunca perdió de vista que su puesta en funcionamiento supondría para la monarquía borbónica haber alcanzado la cumbre de la reforma pretendida.

Así que en 1756 cuando la administración central dio por terminado el Catastro, las oligarquías locales se aprestaron a hacer una protesta institucionalizada sirviéndose de la Diputación del Reino. El resultado fue una representación manuscrita que resulta clave para entender por qué no llegó a aplicarse la Única; era, en definitiva, una llamada de atención del Reino a las pretensiones del Rey de fortalecer su poder absoluto. Dicho documento es extenso y, girando alrededor de la nueva Contribución, consta de dos piezas perfectamente delimitadas: la primera, con manifestaciones más generales, se centra en la mencionada llamada de atención o en las entonces casi inexistentes relaciones entre el Rey y el Reino, y la segunda aporta concretas objeciones a la Única ${ }^{17}$.

\footnotetext{
17 Congaeso de los Diputados (Madrid). "Cortes de Castilla", leg. 22, n. ${ }^{\circ}$. La noticia de este documento que, a la espera de otros criterios, juzgo todavia inédito se la debo a J.M. Carretero.
} 
Fue redactado en nombre de la "Diputación de los Reinos de las Coronas de Castilla, León y Aragón" por cuatro de sus miembros que se presentaron a sí mismos como "procuradores de las ciudades": D. Cristóbal del Peso, por Ávila; D. Martín de Vera, por Córdoba; D. José Márquez, por Segovia y D. Jerónimo Saxs, por Jaca. En una anotación final se indica que fue puesto en manos del Rey «en nombre del Reino" el 19 de septiembre y que aquél, "con particular manifestación de agrado", dijo "que lo mandaria ver". El hecho de que en su elaboración participara el representante de la Corona de Aragón no puede ser dejado de lado porque significa que estamos ante una queja general de toda la Monarquia.

Comenzaba su primera parte, con las debidas muestras de adhesión y respeto a la monarquía, haciéndose eco casi literalmente de lo manifestado por Fernando VI en sus Decretos de 1749:

«Hace presente a V.M. ha llegado a su noticia que inspirado de su real católico celo y del incomparable amor a sus vasallos, desea darlos último testimonio de su benignidad llenándolos de beneficios y alivios para enriquecerlos y fomentarlos por medio del establecimiento de una Contribución que suprima las que bajo el nombre de rentas Reales, servicios de Millones y otros ramos y derechos, se han exigido y exigen actualmente: esto es, que generalmente pague cada uno, a proporción de sus haberes y haciendas que gozan, aquella cuota que corresponda a la más justa equidad, de modo que no sean perjudicados entre sí ni lleve el pobre más carga que la que sus fuerzas permitan. La Diputación, Señor, en quien reside la representación del Reino en su ausencia, por sí y en su nombre, reconvenida de su propia obligación y de aquel amor sin término que profesa a V.M., rinde desde luego las más reverentes gracias por la celosa fatiga y desvelo que V.M. se toma en una empresa tan a todas luces grande como la de consolarlos por este medio para que alienten y respiren y en lo sucesivo contribuyan con más comodidad y sea V.M. más bien servido".

El exordio no carecía de ironía, y dejaba entrever una principal queja: que al Reino, representado por su Diputación, no se le había pedido opinión alguna 0 , de otro modo, que para el rey y sus ministros no contaba el Reino. Resulta por ello del máximo interés la continuación del escrito, porque sin ambages incitaba al rey a que no olvidara cuál había sido la relación tradicional del Reino con sus monarcas:

"Formóse, Señor, el Erario y Patrimonio de esta Corona con las innumerables repetidas concesiones y servicios del reino que, como deuda de justicia a sus monarcas, crecieron y se aumentaron a proporción de los gastos y urgencias que traen consigo los Imperios grandes. No alcanza el guarismo a numerar su importe ni se hace creible aun teniéndolos a la vista, porque superando su celo a las fuerzas, en la necesidad de socorrerlas suavizaron con el modo de la contribución, y para que se hiciese efectiva y cuasi insensible a los vasallos usó del más primoroso artificio (esto era, el recurso a los procedimientos indirectos de cobro) que cabe en la comprensión humana...". 
Tras dar las gracias al rey y a sus ministros por lo que se estaban esforzando "para darle el punto" (sic) a la Única -lo cual significaba que a juicio de la Diputación aún no estaba en condiciones para salir a la circulación-, consideraba que era su obligación dar el parecer sobre al asunto aun a sabiendas de que éste no le habia sido solicitado: "Para que V.M. se halle enterado, ha parecido a la Diputación exponer a su real consideración..." que ya Felipe IV justamente un siglo antes tuvo intención "de reducir las contribuciones de que ahora se trata a una sola, que es el mismo concepto de V.M." para todos los vasallos, "también para los más ricos y acomodados sin alguna excepción» Pero entonces, y a diferencia de ahora, el rey la había expuesto a las Cortes para su consideración de suerte que éstas pudieron aportar su opinión y redactar un acuerdo.

Y para poner de relieve el malestar del Reino, los redactores del escrito, incluyendo una copia íntegra de aquél, explicaban por qué la postura de Felipe IV había sido la correcta:

\begin{abstract}
"A esto se reduce el Acuerdo, por que habiendo nacido el rey y el reino a un mismo tiempo, si el primero como suprema cabeza para mandar con autoridad soberana, el segundo sujeto a las leyes de la obediencia, como el concurso de las dos partes en su debida proporción, por medio de esta indivisible unión, son el constitutivo de la Corona, quiso (Felipe IV) honrar al Reino haciéndolo saber su voluntad para que la tuviese entendida en fuerza de los reciprocos contratos que han intervenido entre los monarcas y su Reino en varios acuerdos autorizados y celebrados con motivo de la concesión de antiguos y actuales servicios, en los cuales para su mayor validación, demás de la fe y real palabra fueron solemnemente aceptados y convertidos en Leyes y Pragmatica Sanción establecidas y promulgadas en Cortes, y con todas las demás firmezas de conciencia y justicia que inducen a su mayor observancia y cumplimiento..."
\end{abstract}

Esta última frase no dejaba de ser un aviso de que la Única podía fracasar si era impuesta mediante un Decreto y no por una Ley. Reflejaba a continuación la Diputación ser conocedora de los pasos que el rey había dado hasta entonces, contrariamente a lo afirmado al principio del escrito; cómo, en primer lugar, había consultado a una Junta de peritos del derecho - presidida por el Gobernador del Consejo de Castilla- sobre la viabilidad legal de la nueva Contribución. Cómo, luego, y con el dictamen favorable de aquélla, había creado otra para que se ocupara de los problemas prácticos previos, esto era, de hacer un Catastro:

"formó Instrucciones para la inquisición de las haciendas de los vasallos en to general del Reino; diputó y envió ministros a todas las provincias para su exacta y prolija averiguación, dando reglas, providencias y solución a las dudas y reparos que se iban ofreciendo; reguló los productos; se hicieron infinitos planos 
en cada una midiendo terrenos y heredades en que cargar y proporcionar la Contribución, de más de la relación jurada que dio cada vasallo de la hacienda que posee $y$, finalmente, no cabe en la ponderación lo que ha trabajado (la Junta) en el asunto hasta acercarse y hacer un prudente tanteo por el que se vea el alivio del Reino sin disminución del Erario de V.M. que es el objeto".

$Y$ cómo, por fin y teniendo los resultados pretendidos, había formado una tercera Junta para que su dictamen final se convirtiera en la decisión del rey para establecer la Contribución.

Hasta aquí todo lo que de su parte habian hecho el rey y sus ministros, y que estaba bien hecho. Pero faltaba todavia, como así habia sido en los siglos anteriores, el beneplácito del Reino - «mas como los intereses de V.M. y los del Reino son un solo interés, de cuyo nivel y proporción resulta un recíproco bien y utilidad conveniente para la conservación del Estado...»-; de otro modo, poner en marcha la Única sin el Reino sería un acto contrario a la Constitución histórica de la monarquía.

"La gravedad del negocio" requería que la Diputación fuera consultada; porque la nueva medida que se iba a tomar era revolucionaria, "el mayor y más arduo que puede ocurrir en cuanto se trata de una mutación general en el Patrimonio de esta Corona, establecido lentamente en el discurso de algunos siglos, en los que los vasallos se han ya acostumbrado". Y era asunto grave en especial para el futuro de la institución de las Cortes porque la supresión de las Rentas Provinciales - que por naturaleza eran subsidios temporales concedidos por el Reino aunque en el momento estuvieran prorrogados - para dar entrada a una perpetua Contribución, implicaba el fin de aquéllas y, por ende, de su Diputación

A continuación, y sin más dilaciones, dicha Diputación "dándose por consultada" pasaba a hacer su propuesta consistente en que antes de que la Junta tomara la decisión final que el rey haría suya, se sirviera aquélla oir a las ciudades de voto sobre la materia para garantizar su éxito. Con astucia añadía que no hacia falta convocarlas en Cortes («sin unión de Congreso por los embarazos y dilaciones que éste pudiere causar») sino que fueran preguntadas separadamente de forma que

"digan lo que entendieren y se les ofreciese para la ejecución del propuesto pensamiento, pues como más experimentales informará cada una por su Provincia originalmente no sólo la situación en que se halla, sino todo lo conducente a la plantificación del nuevo establecimiento, comunicando luces y noticias que al vez no puede percibir desde aquí ni los supuestos hechos...".

Bien sabia la Diputación que los poderes a los que representaba, y eran los que habían promovido el escrito, pondrían todo género de dificultades..., 
como también lo sabían el rey y sus Juntas puesto que habian evitado consultarlas.

$Y$ finalizaba diciendo: «V.M. no obstante lo referido como real soberano dueño del reino, con la suprema autoridad que le compete, se dignará resolver lo más conforme a su real voluntad...", pero era deber de la Diputación avisar de los riesgos que la empresa podía conllevar por no contar con el Reino.

La segunda parte, redactada con términos mucho más precisos y sin los circunloquios de la primera de suerte que parece estar destinada a ser estudiada por la Junta decisoria, comenzaba recogiendo las principales ideas de aquélla; porque si las Rentas Provinciales eran una concesión del Reino al Rey, la contribución que las iba a sustituir también debía serlo, lo que implicaba que el Reino debía ser consultado ya que sobre éste iba a recaer la misma. Y que pese a no haber sido consultado así como tampoco su Diputación «en negocio de tanta gravedad, tocado varias veces en los siglos pasados, pero sin efecto por las dificultades que pudieron suspender su ejecución", ésta "por descargo de su conciencia» se veía obligada a exponer una serie de precauciones si bien eran las ciudades -repetía- las competentes para poder ofrecer "la luz conveniente».

Detrás de estas precauciones, realizadas "en nombre del Reino", es fácil adivinar a los poderes locales intentando defender sus intereses adquiridos, tal y como procedería la burguesía liberal en el siglo siguiente. Ordenadas las cuestiones según su importancia, un primer grupo recordaba las regalías y contratos que el Reino tenía estipulados con los monarcas para evidenciar que Fernando $\mathrm{VI}$ con su proceder no los estaba teniendo en cuenta, y el resto planteaba algunas dificultades generales con las que podía encontrarse la nueva contribución "pues se alteraba la costumbre».

"Lo primero. Tuvieron presente que las rentas que se van a suprimir nacen de concesiones del Reino junto en Cortes y servicios temporales hechos a S.M. para la precisa conservación del Estado, los cuales vendrán a perpetuarse con este nuevo establecimiento".

"Lo segundo. Que los tales servicios se concedieron con motivo de urgentes necesidades y precisa aplicación de ellas, reservándose el Reino su administración para que los Ministros de S.M. con perjuicio de su servicio y del Estado no los convirtiesen en otros fines distintos de aquellos para que se concedieron". Por el contrario, en el momento presente estaban en manos de los ministros de Hacienda y sus funcionarios.

“ (...) Lo cuarto. Que en tales asuntos, en cualquiera urgencia que ocurría se contaba con el Reino, a quien S.M. la hacia entender para que pensase y acordase el modo de socorrerla, porque como éste reflexionaba el medio 
Los decretos de la Real Hacienda de 1749, los poderes locales y la representación...

menos sensible para los vasallos y más pronto para la exacción, que es el mayor primor de toda imposición, nadie con más experiencia y mayor celo podía ni debía encontrarle».

$Y$ aún más. En el punto siguiente se decía que ese procedimiento de recaudación - el indirecto- había sido una condición puesta por el Reino a los monarcas a cambio de concederles los servicios solicitados por lo cual la obligación de éstos era conservarlo, «por contrato reciproco oneroso y con fuerza de Ley promulgada en Cortes".

Sobre la cuestión de sustituir las Rentas Provinciales por la Única Contribución:

"Lo sexto. Que el Reino se reservó la facultad de que los servicios que ha concedido, ni aun en el modo ni el nombre pudiesen alterarse, ni subrogar otros en su lugar sin consentimiento suyo, pues esto sólo a él pertenecía".

Por otra parte, era misión exclusiva del Reino precisamente cumplir el objetivo para el que se decía que llegaba la Única, a saber, la percepción de cantidades que sólo "puramente fuesen carga de justicia del Estado» evitando otras que condujesen a "excusar gastos superfluos" (punto séptimo). De otra manera, si la excusa para introducir la Única era ésa, sobraba.

Luego, la Diputación pasaba a relatar los problemas que podía traer la nueva Contribución o lo poco que podia «aliviar" los existentes según el "sentir general" del Reino, no sin antes dejar sentado que, puesto que en ella residía "la autoridad del Reino en cuanto a mantener sus regalías y derechos", lo hacía en virtud del juramento hecho a éste (punto octavo).

Recogía una queja general que iba a hacerse permanente en los sucesivos intentos de implantar la Única; que si se utilizaba el Catastro como referencia, aunque periódicamente fuese revisado, como lo fue en 1760 y 1770 , se cometerian muchas injusticias al asignar las cantidades a los individuos, porque para aquél todos los años agrícolas eran buenos o todos los años los comerciantes vendían lo mismo.

"Lo nono. Que una novedad tan general podria alterar todo el Común del Reino, llenándole de quejas y agravios nacidos de la valuación y repartimiento que cada uno deberia contribuir por la declinación de los bienes raíces y semovientes, años estériles, falta de cultivo, y el ningún punto fijo que se puede dar en tráficos y comercios, sin presupuesto seguro ni aquella equidad y proporción que S.M. y el Reino desean".

Y una observación que provenía directamente de los hasta hacía poco recaudatarios beneficiarios de las Rentas Provinciales; que si bien la 
Única llegaba aparentemente para simplificar las cosas, su cobro iba a ser mucho más complicado -individuo a individuo - e iba a provocar un elevado número de quejas, por lo que sería precisa mucha más gente dedicada que hasta entonces y, consecuentemente, un considerable aumento de gastos para el Erario.

"Lo décimo y de profunda consideración es que la mayor dificultad estará en la exacción de lo que se reparta, para cuya cobranza habrá más ministros ejecutores y mayores gastos que hoy, siendo indispensable oir a los vasallos sus recursos en justicia para indemnizarlos si se les hiciese agravio; de más de que por un movimiento tan universal, transmigración y división de las haciendas, continuamente deberán hacerse nuevos repartimientos por sus repetidas mutaciones y novedades, multiplicando inconvenientes y embarazos, y dilatando o imposibilitando la cobranza".

Por lo demás la Única tampoco iba a aportar alivio en la vida cotidiana de las gentes.

"Lo undécimo. Que el alivio que se cree podrán tener los vasallos en la moderación de precio de toda suerte de alimentos, puede tal vez no verificarse; porque como el gravamen de esta nueva Contribución ha de seguir al fruto y de él ha de salir, será difícil conseguirla; en cuyo caso se hallarán los vasallos en peor estado que hoy, y la imposibilidad en ellos será mayor".

Y como la futura Contribución venía a gravar todo tipo de renta, no sólo la de bienes inmuebles, todo el Reino se vería afectado en mayor o menor medida. De una parte los pueblos, en cuanto tales, iban a empeorar su situación porque al tener que pagar una contribución por sus rentas de Propios y arbitrios tendrían que rebajar sus presupuestos destinados a las atenciones comunitarias.

«Lo duodécimo. Los gravámenes que ya tienen sobre si los pueblos, empeñados sus arbitrios, cargados con censos y otras obligaciones en fuerza de Reales facultades, para cuyo gasto se aumentará el regular repartimiento".

De otra, el mundo rentista que habia invertido en juros también iba a empeorar porque debería contribuir por ser titular de unos intereses que en la práctica apenas los estaba pagando el Estado.

"Lo decimotercio. La carga de juros y modo de reglarla en que todo el común del Reino es interesado. Teniendo tanta parte lo sagrado, pío, como el estado secular». 
$Y$, por supuesto, la sustitución de las Rentas Provinciales por la Única iba a afectar a los muchos privilegiados - particulares e instituciones- a quienes los diversos monarcas habían concedido la propiedad de su percepción, máxime cuando quedaba al arbitrio de Hacienda y sus ministros la posibilidad de ser indemnizados:

"Lo décimo cuarto. Que suponiendo que la real Hacienda haya de satisfacer estas cargas (los intereses de los juros), la de alcabalas y otras a sus vasallos por descontado se les quita la propiedad, dominio y libre uso sin recurso si la urgencia del Estado no permite su paga".

Pero, si bien se mira, esto no sería más que la culminación del asalto ilustrado a los mencionados privilegiados que ya había pasado por dos fases previas: la derivada del Decreto de 1749, por el que habian quedado en manos de Hacienda las Rentas Provinciales, y la del de agosto de 1754 que había declarado que en adelante todas las rentas, no sólo las Provinciales, quedaban bajo su control:

"Declaro que deben correr por mano de mi Secretario de Estado y del despacho universal de Hacienda todos los asuntos pertenecientes a mis Rentas, a los Maestrazgos, a las tres gracias de Cruzada, Subsidio y Excusado; a las enajenaciones de a Corona e incorporaciones a ella; a la Regalía de la casa de aposento; al comercio y fábricas; a las gracias llamadas "al sacar", que consulta la Cámara; y a todos los demás efectos y derechos de mi Real Hacienda..." ${ }^{18}$.

$Y$, por fin, la entrada de la Única, y la eliminación de las Rentas Provinciales, supondría agravar los problemas que de por sí venían teniendo los comerciantes españoles en su competencia con los extranjeros.

"Décimo quinto. Que siendo innumerables los extranjeros que frecuentemente vienen a estos Reinos vagantes, sin radicarse ni establecerse en ellos, si sólo al recogimiento de nuestra plata y sustancia para retirarse con ella a su país, dejándonos en recompensa inútiles despreciables bugerias, (si) los cuales contribuyen hoy insensiblemente apenas ponen el pie en ellos, será dificultoso que por medio de esta Única Contribución lo hagan mañana y que se les reparta gabela alguna, de que las Naciones puedan resentirse por no estar acostumbrados a ella, cargando así todo el peso en los naturales" ${ }^{19}$.

Acababa la Diputación su relación de puntos con una observación política que, agitada convenientemente, podía resultar definitiva para que la totalidad del Reino nunca aceptara la Única.

18 Nov. Recop., libro III, tit. VI, ley X.

19 Congreso de los Diputados, ibidem. 
"La décima sexta. Que el proyecto que intenta ponerse en ejecución en España por medio de esta Contribución, es alusivo en la mayor parte al que el Mariscal de Vauban publicó en París para destruir la talla en Francia como gravosa, el cual viene a reducirse a una décima real de los frutos de la tierra, y otros que no tuvo efecto, y aun cuando le hubiera tenido, no haría consecuencia a esta Monarquia".

Esta representación escrita que se había esforzado en mostrar que, en definitiva, el rey y sus ministros estaban solos frente al Reino acabó con lo que al inicio de este artículo he llamado intento de "golpe de la nueva Monarquía», porque a partir de 1756 comenzaron su «largo peregrinar sin final» los distintos proyectos reformistas por implantar la Única de suerte que llegarían a entrar en el siglo XIX. Y ya que habían vencido los poderes locales, cabezas visibles del Reino, la monarquía hubo de acabar pactando con ellos para mantenerse. Asi que cuando Cabarrús presentó en 1784 su Proyecto de Única Contribución, que era mucho más radical que el de Ensenada, el ministro Floridablanca comento al conde de Gausa: "Una novedad de esta naturaleza podría ser muy aventurada en su ejecución y en sus efectos, y exponernos si no preceden otros conocimientos, cálculos y experiencias, a una convulsión espantosa en el orden económico y en todo lo que de él depende e interesa al Rey y a la Nación» ${ }^{20}$. 